DOI: 10.15587/2706-5448.2022.251351

Article type «Reports on Research Projects»

\section{Yan Liu, Zhenhua Duan, Sergey Sabadash, Feifei Shang}

\title{
STUDY ON THE EFFECT OF INTERMITTENT MICROWAVE DRYING CONDITIONS ON THE BIOACTIVE COMPOUNDS AND ANTIOXIDANT CAPACITY OF BEETROOTS
}

The object of this research was the beetroots prepared by intermittent microwave drying at different conditions. The paper aimed to investigate the influence of intermittent microwave drying conditions (power density, microwave gap ratio and slice thickness) on the bioactive compounds and antioxidant capacity of beetroots. A microwave drying system SAM-255 (CEM Corporation, USA) was used to intermittent microwave drying of fresh beetroots. The effect of different power densities $(1.0,1.5,2.0$, and $2.5 \mathrm{~W} / \mathrm{g})$, microwave gap ratios $(1,2,3$, and 4) and slice thicknesses $(2,4,6$, and $8 \mathrm{~mm})$ on the bioactive compounds and antioxidant capacity of beetroots were investigated. Colorimetric methods were used to determine contents of betalains, total phenolic and total flavonoid, and antioxidant capacity of dried beetroots. The ascorbic acid content was determined using 2,6-dichloroindophenol titration method.

Results showed that power density, microwave gap ratio and slice thickness significantly affected the drying time, bioactive compounds and antioxidant capacity of beetroots. The drying time decreased with the increasing of power density, while increased significantly with the growth of slice thickness and microwave gap ratio. The shortest drying time (35.4 $\pm 2.6 \mathrm{~min}$ ) of beetroots was occurred at microwave gap ratio of 2. The content of betacyanins was found to be the highest in the dried beetroots with thickness of $2 \mathrm{~mm}$. The beetroots with slice thickness of 2 and $4 \mathrm{~mm}$

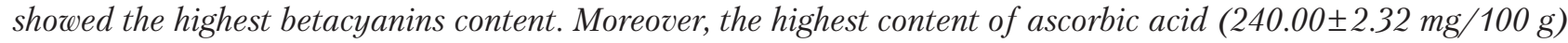
and total flavonoid $(14.52 \pm 0.06 \mathrm{mg}$ rutin equivalent $(R E) / \mathrm{g}$ ) was appeared at power density of $2.0 \mathrm{~W} / \mathrm{g}$, while the content of total phenolic to be highest $(12.54 \pm 0.13 \mathrm{mg}$ gallic acid equivalent (GAE)/g) at slice thickness of $6 \mathrm{~mm}$. For the antioxidant capacity of dried beetroots, the 1,1-diphenyl-1-picrylhydrazyl (DPPH) radical scavenging activity reached to the highest value of $6.43 \pm 0.03 \mathrm{mg}$ trolox equivalent (TE)/g at power density of $2.5 \mathrm{~W} / \mathrm{g}$. While the highest values of ferric-reducing antioxidant power (FRAP) $(15.47 \pm 0.10 \mathrm{mg} T E / \mathrm{g})$ and 2,2'-azino-

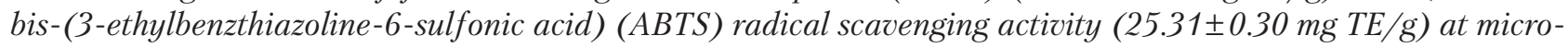
wave gap ratio of 2 . It was found that ABTS radical scavenging ability and FRAP were related to the presence of reductions including betalains, ascorbic acid, and total flavonoid in beetroots.

The most effective condition for intermittent microwave drying of beetroots were microwave gap ratio of 2 , power density of $2.0 \mathrm{~W} / \mathrm{g}$, and slice thickness of $4 \mathrm{~mm}$, leads to a better preservation of bioactive compounds and high antioxidant capacity.

Keywords: intermittent microwave drying, beetroot, betalains, total phenolic, antioxidant capacity.

\section{How to cite}

Liu, Y., Duan, Z., Sabadash, S., Shang, F. (2022). Study on the effect of intermittent microwave drying conditions on the bioactive compounds and antioxidant capacity of beetroots. Technology Audit and Production Reserves, 1 (3 (63)), 23-30. doi: http://doi.org/10.15587/2706-5448.2022.251351

\section{Introduction}

Beetroot (Beta vulgaris L.) is a valuable vegetable due to its high content of bioactive compounds with antioxidant activity, such as betalains, ascorbic acid, polyphenols, flavonoids, carotenoids and saponins, as well as important minerals such as potassium, calcium and sodium, are also a source of dietary fiber $[1,2]$. Nowadays, beetroot is grown in a lot of countries all over the world and frequently consumed in daily life. It was estimated that the world production of beetroot was 275.49 million metric tons in 2018 [3]. Beetroot is commonly consumed fresh as well as cooked, pickled, or canned [4], which is especially used as the main ingredient of borsch in Eastern Europe. Borsch is a sour soup that is popular in Ukrainian, Romanian, Moldavian, Belarusian, Latvian, Lithuanian, Russian and 
Polish cuisines [5]. Beetroot widely used as food colorant or additive in food products, such as yogurts, ice cream and other products. The beetroot extracts are often used to improve the redness in soups, tomato pastes, desserts, sauces, jellies, jams, sweets and breakfast cereals [1].

Fresh beetroot is prone to spoilage due to its high moisture content. Drying plays a vital role in prolonging shelf life of fresh perishable foods such as fruits and vegetables, reducing packaging costs as well as reducing the weight of transportation [6]. Convective hot air drying is the most commonly used method in food drying, but due to the low thermal conductivity of food materials, its main disadvantages are low energy efficiency, long drying time, great loss of nutritional value and physical properties (shrinkage, color) [7, 8].

Microwave drying is a good alternative way to preserve heat-sensitive compounds, save time and reduce energy consumption [9]. However, microwave drying also has some disadvantages, including uneven electric field distribution leading to non-uniform heating, limited penetration depth and possible texture damage [10]. Moreover, it also leads to the occurrence of hot spots, which may result in charring and off flavors [11]. Therefore, it has been proven that intermittent microwave drying is an alternative method, which can avoid the redistribution of temperature and moisture distribution in the product due to thermal diffusion during microwave heating, thereby avoiding uneven heating, reducing hot spots, improving product quality and energy efficiency [12].

During the intermittent microwave drying process, the bioactive compounds and antioxidant capacity of beetroots might be lost. The aim of this research was to investigate the effect of intermittent microwave drying conditions on the bioactive compounds and antioxidant capacity of beetroots. Important factors, including microwave gap ratio, power density and slice thickness, were used to design experiments. The drying time, bioactive compounds and antioxidant capacity of beetroots were used to evaluate levels of influence in each factor. Thus, the object of research is the beetroots prepared by intermittent microwave drying at different conditions.

\section{Research methodology}

Fresh beetroots (Beta vulgaris L.) were purchased from a local market in the city of Xuzhou in Jiangsu Province, China. The average initial moisture content of fresh beetroot was $92.32 \pm 1.37 \%$ (wet basis). Before drying, beetroots were stored in a refrigerator at $4{ }^{\circ} \mathrm{C}$. Beetroots were washed by running water to remove impurities. The washed beetroots were peeled and then cut transversely with a stainless steel slicer, chopped into slices of different thicknesses with a diameter of $80 \mathrm{~mm}$.

The one-factor-at-a-time method was applied in this study to design experiments with three replications. Investigated factors include power density, microwave gap ratio and slice thickness. The fresh beetroot slices were carefully placed into a circular fiberglass tray (diameter $=300 \mathrm{~mm}$ ). The circular fiberglass tray was put into a microwave drying system SAM-255 (CEM Corporation, USA) for continuous dehydration at different power densities (1.0, 1.5, 2.0 , and $2.5 \mathrm{~W} / \mathrm{g})$, microwave gap ratios $(1,2,3$, and 4 ) and slice thicknesses $(2,4,6$, and $8 \mathrm{~mm})$. The drying process was stopped when the moisture content of beetroot slices approached about $10.0 \pm 1.0 \%$ (wet basis), which was considered the final moisture ensuring safe storage.

Extraction of bioactive compounds. Dried beetroots obtained from triplicate were mixed and then grounded into powder (pass through a 60-mesh sieve) to obtain samples with representative chemical components for particular drying conditions. Beetroot powder sample $(2.0 \mathrm{~g})$ was place in a centrifuge tube, $20 \mathrm{~mL}$ of $50 \%$ ethanol (v/v) was added, and then mixed by a vortex mixer VORTEX-5 (KylinBell Instrument Manufacturing Co., Ltd, Jiangsu, China) for 2 min. After centrifugation (H1850, Xiangyi Centrifuge Instrument Co., Ltd, Hunan, China) at $5000 \mathrm{rpm}$ for $10 \mathrm{~min}$, the supernatant was collected and the sample residue was extracted twice with $20 \mathrm{~mL}$ of $50 \%$ ethanol $(\mathrm{v} / \mathrm{v})$. The combined supernatants were adjusted to $100 \mathrm{~mL}$ with $50 \%$ ethanol (v/v). The extracts were stored at $4{ }^{\circ} \mathrm{C}$ until further analysis of bioactive compounds (betalains, ascorbic acid, total phenolic, total flavonoid) and antioxidant capacity.

Betalains can be divided into two groups: red-violet betacyanins $\left(\lambda_{\max }=538 \mathrm{~nm}\right)$ and yellow-orange betaxanthins $\left(\lambda_{\max }=480 \mathrm{~nm}\right)$. The betalains content was conducted by the method as described in [13]. The extracts were diluted with $0.05 \mathrm{~mol} / \mathrm{L}$ phosphate buffer solution ( $\mathrm{pH}$ 6.5) to obtain absorption values of $0.8 \leq A \leq 1.0$ at $538 \mathrm{~nm}$. Absorptions of betaxanthins, betacyanins, and non-betalain substances were measured using a spectrophotometer $722 \mathrm{~N}$ (Precision Scientific Instruments Co., Ltd, Shanghai, China) at 480, 538 and $600 \mathrm{~nm}$, respectively. The betalains content (BC) was calculated by the following equation:

$$
B C(\mathrm{mg} / \mathrm{L})=\frac{A \cdot D F \cdot M W \cdot 1000}{\varepsilon \cdot l}
$$

where $A$ is the absorption value at the absorption maximum corrected by the absorption at $600 \mathrm{~nm}$. $D F$ the dilution factor, and $l$ is the path length $(1 \mathrm{~cm})$ of the cuvette. For quantification of betacyanins and betaxanthins, the molecular weights $(M W)$ and molar extinction coefficients $(\varepsilon)$ of betanin $(M W=550 \mathrm{~g} / \mathrm{mol} ; \varepsilon=60000 \mathrm{~L} /(\mathrm{mol} \cdot \mathrm{cm})$ in $\left.\mathrm{H}_{2} \mathrm{O} ; \lambda=538 \mathrm{~nm}\right)$ and indicaxanthin $(M W=308 \mathrm{~g} / \mathrm{mol}$; $\varepsilon=48000 \mathrm{~L} /(\mathrm{mol} \cdot \mathrm{cm})$ in $\left.\mathrm{H}_{2} \mathrm{O} ; \lambda=480 \mathrm{~nm}\right)$ were applied. The betalains content was expressed as mg betanin equivalent $(\mathrm{BE}) / \mathrm{g}$ for betacyanins and $\mathrm{mg}$ indicaxantin equivalent (IE)/g for betaxanthins.

The ascorbic acid content was determined using 2,6-dichloroindophenol titrimetric method as described in [14]. 2,6-dichloroindophenol (DCPIP) is a blue dye, generates a distinguished rose-pink color in acidic conditions. DCPIP can form a colorless solution when reacting with ascorbic acid. Thus, the adding of ascorbic acid into an acidic aqueous DCPIP solution drives its rose-pink color faded continuously into colorless. The end-point was detected when excess DCPIP gave a light but distinct rose pink color that persisted for more than $10 \mathrm{~s}$. The DCPIP solution was standardized using a standard solution of ascorbic acid. The ascorbic acid content was expressed as milligrams per $100 \mathrm{~g}$ of dry weight $(\mathrm{mg} / 100 \mathrm{~g})$.

Total phenolic content (TPC) was evaluated using FolinCiocalteu method [15]. Diluted sample extract $(0.5 \mathrm{~mL})$ was mixed with $2.5 \mathrm{~mL}$ of $10 \%$ Folin-Ciocalteu reagent (v/v), and then $2 \mathrm{~mL}$ of $7.5 \%$ sodium carbonate $(\mathrm{w} / \mathrm{v})$ was added. The mixture was incubated at $50{ }^{\circ} \mathrm{C}$ for $15 \mathrm{~min}$ and cooled to room temperature, and the absorbance was read at $760 \mathrm{~nm}$. Results were expressed as $\mathrm{mg}$ of gallic acid 
equivalent (GAE) per g of dry weight based on a calibration curve using gallic acid as a standard at concentrations of $0-0.1 \mathrm{mg} / \mathrm{mL}$.

Total flavonoid content (TFC) was determined by the aluminum chloride colorimetric method with some modifications [16]. Sample extract $(1 \mathrm{~mL})$ was mixed with $4 \mathrm{~mL}$ of $50 \%$ ethanol $(\mathrm{v} / \mathrm{v})$ and $0.5 \mathrm{~mL}$ of $50 \% \mathrm{NaNO}_{2}$ solution $(\mathrm{w} / \mathrm{v})$ in a $10 \mathrm{~mL}$ tube. After $6 \mathrm{~min}$ of reaction, $0.5 \mathrm{~mL}$ of $10 \% \mathrm{AlCl}_{3}$ solution $(\mathrm{w} / \mathrm{v})$ was added to the tube. After $6 \mathrm{~min}, 4 \mathrm{~mL}$ of $1 \mathrm{~mol} / \mathrm{L} \mathrm{NaOH}$ was added. The above solution was mixed thoroughly and left to stand for $10 \mathrm{~min}$. The absorbance was recorded at $510 \mathrm{~nm}$. A calibration curve was obtained using different concentrations $(0-500 \mathrm{mg} / \mathrm{L})$ of rutin. TFC was expressed as $\mathrm{mg}$ of rutin equivalent (RE) per $g$ of dry weight (mg RE/g).

Beetroots contain a wide variety of phytochemicals that function as antioxidants. This study evaluated the antioxidant capacity of dried beetroots by three methods (2,2-diphenyl1-picryl-hydrazyl radical scavenging capacity, ferric-reducing antioxidant power, and 2,2'-azino-bis-(3-ethylbenzthiazoline6 -sulfonic acid) radical scavenging capacity).

The 2,2-diphenyl-1-picryl-hydrazyl (DPPH) assay was analyzed using the colorimetric method, reported in [17] with minor modifications. The DPPH assay was performed by adding $2 \mathrm{~mL}$ of diluted extract to $4 \mathrm{~mL}$ of $0.2 \mathrm{mM}$ $\mathrm{DPPH}$ solution and reacting for $30 \mathrm{~min}$ at room temperature in the dark. The absorbance of the mixture was read at $517 \mathrm{~nm}$. A calibration curve with trolox at concentrations of $0-150 \mu \mathrm{mol} / \mathrm{L}$ was used. Results were expressed as milligrams trolox equivalent (TE) per gram of dry weight (mg TE/g).

The ferric-reducing antioxidant power (FRAP) assay was conducted by the method proposed by authors of paper [18]. First of all, FRAP reagent was prepared by mixing $0.01 \mathrm{M}$ TPTZ solution (prepared in $0.04 \mathrm{M}$ $\mathrm{HCl}), 0.02 \mathrm{M} \mathrm{FeCl}_{3}$ solution and $0.3 \mathrm{M}$ acetate buffer $(\mathrm{pH} \mathrm{3.6)}$ at the volumetric ratio of 1:1:10. The diluted extract $(0.2 \mathrm{~mL})$ was fully reacted with $6 \mathrm{~mL}$ of FRAP reagent. After incubating at $37{ }^{\circ} \mathrm{C}$ for $10 \mathrm{~min}$, the absorbance at $593 \mathrm{~nm}$ was recorded. A calibration curve was obtained using different concentrations $(0-600 \mu \mathrm{mol} / \mathrm{L})$ of trolox. All solutions were prepared on the day of use. Results were expressed as trolox equivalent (TE) in $\mathrm{mg} / \mathrm{g}$.

The 2,2'-azino-bis-(3-ethylbenzthiazoline-6-sulfonic acid) (ABTS) assay was slightly modified from the method as described in [19]. Equal quantities of $2.45 \mathrm{mM} \mathrm{K}_{2} \mathrm{~S}_{2} \mathrm{O}_{8}$ solution and $7 \mathrm{mM}$ ABTS were mixed to obtain $\mathrm{ABTS}^{\circ+}$ solution. The $\mathrm{ABTS}^{-+}$solution was allowed to stand for $16 \mathrm{~h}$ at room temperature in the dark. The $\mathrm{ABTS}^{*+}$ solution was diluted with $80 \%$ ethanol $(\mathrm{w} / \mathrm{v})$ to obtain an absorbance of $0.70 \pm 0.02$ at $734 \mathrm{~nm}$ before the measurement. Diluted sample extract $(0.4 \mathrm{~mL})$ was reacted with $3.6 \mathrm{~mL}$ diluted ABTS $^{\cdot+}$ solution for $6 \mathrm{~min}$ at room temperature. Absorbance was read at $734 \mathrm{~nm}$. Trolox with concentrations of $0-140 \mu \mathrm{mol} / \mathrm{L}$ was used as the standard curve. Results were calculated as $\mathrm{mg}$ trolox equivalent per $\mathrm{g}$ of dry weight ( $\mathrm{mg} \mathrm{TE} / \mathrm{g})$.

All experiments were conducted in triplicate and results were expressed as mean \pm standard deviation (SD). Statistical analysis was performed using Microsoft Excel 2007 and IBM SPSS Statistics 20.0 (SPSS Inc., Chicago, IL, USA). The analysis of variance (ANOVA) and Duncan's multiple range test were used to determine significant differences at $95 \%$ confidence level $(p<0.05)$. Origin 9.0 (Origin Lab, MA, USA) was used to draw figures.

\section{Research results and discussion}

3.1. Effect of power density on the bioactive compounds and antioxidant capacity of beetroots. The effect of power density on the intermittent microwave drying of beetroots was investigated at the microwave gap ratio of 2 and slice thickness of $4 \mathrm{~mm}$. The power density is the microwave power received by the unit mass of sample during drying [20]. The results indicated that power density significantly impacted the moisture removal from the beetroots (Fig. 1).

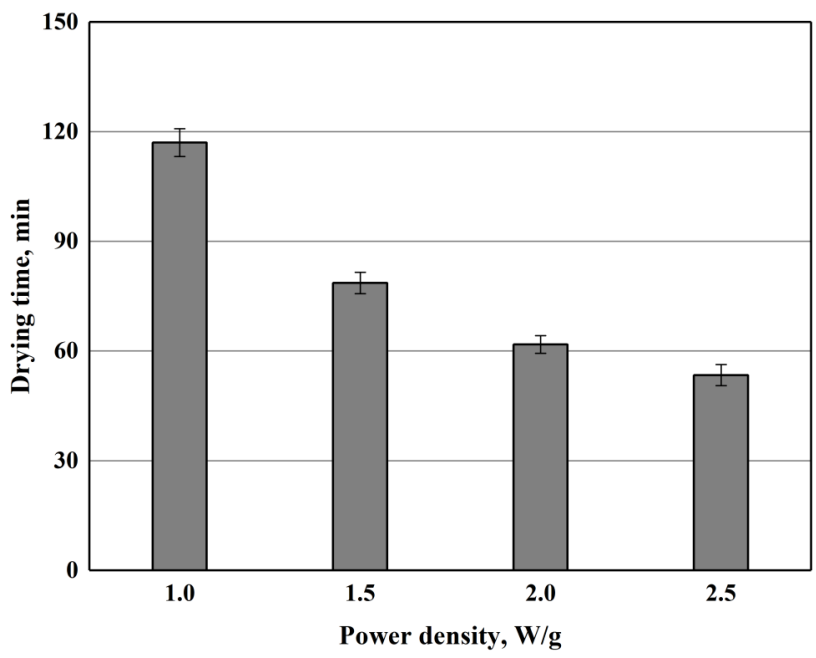

Fig. 1. Effect of different power densities on the drying time of beetroots

As shown in Fig. 1, the drying time of beetroots decreased progressively with rising power density. At high power density, free water within beetroots evaporated in a short time after absorbing much microwave energy. The time to dry the beetroots reduced around $47 \%$ when power density increased double (from 1.0 to $2.0 \mathrm{~W} / \mathrm{g}$ ), and the reduction in drying time became $54 \%$ when the power density was $2.5 \mathrm{~W} / \mathrm{g}$. As it is known, water is the main component which adsorbs and converts energy from microwave radiation to thermal energy used both to vaporize the moisture and heat the materials [14]. Thus, the higher power density was, the more energy was absorbed by the beetroots, leading to accelerating the beetroot drying periods. It was also reported that the drying time decreased significantly when the high level of power density was applied in microwave drying of tomato slices [21] and ginger [22].

Results of betalains, ascorbic acid, total phenolic and total flavonoid contents of dried beetroots at different power densities are exhibited in Table 1. The power density of $2.0 \mathrm{~W} / \mathrm{g}$ resulted in higher contents of betacyanins (1.60 $\pm 0.01 \mathrm{mg} \mathrm{BE} / \mathrm{g})$ and betaxanthins $(1.32 \pm 0.01 \mathrm{mg} \mathrm{IE} / \mathrm{g})$, higher than those of other power densities. The lowest content of betaxanthins $(0.86 \pm 0.01 \mathrm{mg} \mathrm{IE} / \mathrm{g})$ was found in the dried beetroots produced using the lowest power density $(1.0 \mathrm{~W} / \mathrm{g})$, which required longest drying time. The ascorbic acid content of dried beetroots was ranged from $206.78 \pm 1.95$ to $240.00 \pm 2.32 \mathrm{mg} / 100 \mathrm{~g}$ and the beetroots dried at power density of $2.0 \mathrm{~W} / \mathrm{g}$ reached the maximum value $(240.00 \pm 2.32 \mathrm{mg} / 100 \mathrm{~g})$. The TPC of dried beetroots ranged from $9.73 \pm 0.10$ to $10.43 \pm 0.10 \mathrm{mg} \mathrm{GAE} / \mathrm{g}$ (Table 1). Dried beetroots obtained at power density of $1.5 \mathrm{~W} / \mathrm{g}$ showed the highest TPC of $10.43 \pm 0.10 \mathrm{mg} \mathrm{GAE} / \mathrm{g}$. It was observed from Table 1 that the TFC was significantly 
influenced by the power density $(p<0.05)$. The highest TFC $(14.52 \pm 0.06 \mathrm{mg} \mathrm{RE} / \mathrm{g})$ of beetroots was attained by drying at power density of $2.0 \mathrm{~W} / \mathrm{g}$.

Betalains, ascorbic acid, total phenolic and total flavonoid contents of dried beetronts at different power densities

\begin{tabular}{|c|c|c|c|c|}
\hline \multirow{2}{*}{ Bioactive compound } & \multicolumn{4}{|c|}{ Power density, W/g } \\
\cline { 2 - 5 } & 1.0 & 1.5 & 2.0 & 2.5 \\
\hline Betacyanins, mg BE/g & $1.10 \pm 0.01^{\mathrm{c}}$ & $1.20 \pm 0.02^{\mathrm{b}}$ & $1.60 \pm 0.01^{\mathrm{a}}$ & $0.92 \pm 0.01^{\mathrm{d}}$ \\
\hline Betaxanthins, mg IE/g & $0.86 \pm 0.01^{\mathrm{c}}$ & $0.90 \pm 0.01^{\mathrm{b}}$ & $1.32 \pm 0.01^{\mathrm{a}}$ & $0.91 \pm 0.01^{\mathrm{b}}$ \\
\hline Ascarbic acid, mg/100 g & $206.78 \pm 1.95^{\mathrm{b}}$ & $211.40 \pm 3.56^{\mathrm{b}}$ & $240.00 \pm 2.32^{\mathrm{a}}$ & $237.11 \pm 6.14^{\mathrm{a}}$ \\
\hline TPC, mg GAE/g & $9.73 \pm 0.10^{\mathrm{c}}$ & $10.43 \pm 0.10^{\mathrm{a}}$ & $9.99 \pm 0.06^{\mathrm{b}}$ & $9.75 \pm 0.07^{\mathrm{c}}$ \\
\hline TFC, mg RE/g & $10.61 \pm 0.18^{\mathrm{d}}$ & $11.42 \pm 0.31^{\mathrm{c}}$ & $14.52 \pm 0.06^{\mathrm{a}}$ & $13.11 \pm 0.31^{\mathrm{b}}$ \\
\hline
\end{tabular}

Note: different letters in the same row indicate that values аге significantly different $(p<0.05)$ according to the Duncan's test

Notably, the contents of betalains, ascorbic acid and flavonoid were the highest when the beetroot was dried at power density of $2.0 \mathrm{~W} / \mathrm{g}$. Energy radiation from microwave had the power to weaken polar bonds in a molecule, such as betalains, ascorbic acid and flavonoid compounds that have several polar bonds. Those bonds vibrate dramatically under microwave irradiation, which caused the bond rupture to induce chemical reactions [23] and enhanced catalytic reaction. Therefore, the higher the microwave power density was, the faster the degradation reaction was. On the other hand, effect of microwave drying on the degradation of the bioactive compounds in the beetroots is the drying time. The longer drying time was the larger amount of bioactive compounds lost. Thus, it is not surprised at all to observe the contents of betalains, ascorbic acid and flavonoid in the beetroots dried at power density of 1.0 and $1.5 \mathrm{~W} / \mathrm{g}$ was smaller than those at power density of $2.0 \mathrm{~W} / \mathrm{g}$. However, if the microwave power is too large, the sample absorbs more energy, and the bioactive compounds are destroyed, resulting in a decrease in its contents.

At least two methods should be employed to evaluate the total antioxidant capacity due to different mechanisms of antioxidants, such as free radical scavenging, reducing capacity, decomposition of peroxides, prevention of continued hydrogen abstraction, and binding of transition-metal ion catalysts [24, 25]. Therefore, DPPH, FRAP, and ABTS assays were used to determine the antioxidant capacity of the beetroots under various intermittent microwave drying conditions. Antioxidant activities of dried beetroots under different power densities are shown in Table 2.

Table 2

Antioxidant capacity of dried beetroots at different power densities

\begin{tabular}{|c|c|c|c|}
\hline Power density, W/g & DPPH, mg TE/g & FAAP, mg TE/g & ABT5, mg TE/g \\
\hline 1.0 & $4.79 \pm 0.10^{\mathrm{d}}$ & $12.83 \pm 0.10^{\mathrm{d}}$ & $21.37 \pm 0.18^{\mathrm{b}}$ \\
\hline 1.5 & $5.23 \pm 0.03^{\mathrm{c}}$ & $13.07 \pm 0.07^{\mathrm{c}}$ & $21.88 \pm 0.14^{\mathrm{b}}$ \\
\hline 2.0 & $5.68 \pm 0.02^{\mathrm{b}}$ & $15.47 \pm 0.10^{\mathrm{a}}$ & $25.31 \pm 0.30^{\mathrm{a}}$ \\
\hline 2.5 & $6.43 \pm 0.03^{\mathrm{a}}$ & $13.29 \pm 0.07^{\mathrm{b}}$ & $21.71 \pm 0.40^{\mathrm{b}}$ \\
\hline
\end{tabular}

Note: values in the same column with different letters аге significantly different $(p<0.05)$, according to the Duncan's test
It can be seen from Table 2 that the DPPH radical scavenging activity was increased with the increase of power density, reached to the highest value $(6.43 \pm 0.03 \mathrm{mg} \mathrm{TE} / \mathrm{g})$ at power density of $2.5 \mathrm{~W} / \mathrm{g}$. The fer-

Table 1 ric-reducing ability of dried beetroots decreased when the power density increased from 2.0 to $2.5 \mathrm{~W} / \mathrm{g}$. Thus, FRAP was not always proportional to DPPH radical scavenging activity. It was found that the FRAP had a positive correlation with the contents of betalains, ascorbic acid and total flavonoid. The ABTS radical scavenging ability of dried beetroots ranged from $21.37 \pm 0.18$ to $25.31 \pm 0.30 \mathrm{mg} \mathrm{IE} / \mathrm{g}$, and also reached to the highest value at power density of $2.0 \mathrm{~W} / \mathrm{g}$. There was no significant difference $(p>0.05)$ in FRAP values among the power densities of 1.0, 1.5, and $2.5 \mathrm{~W} / \mathrm{g}$.

The lowest values of antioxidant capacity (DPPH, FRAP, and ABTS assays) were found in beetroots dried at power density of $1.0 \mathrm{~W} / \mathrm{g}$. It was reported that long-term exposure to microwave radiation made sensitive components (betalains, ascorbic acid and phenolic compounds) vulnerable to decompose, leading to the reduction in the antioxidant capacity [14]. Therefore, application of higher microwave power density decreased the drying time and in this way could reduce thermal degradation of the compounds responsible for antioxidant activity of dried beetroots [26]. The highest FRAP value and ABTS radical scavenging ability, as well as contents of betalains, ascorbic acid and total flavonoid were found in the beetroots dried at power density of $2.0 \mathrm{~W} / \mathrm{g}$, indicating that FRAP value and ABTS radical scavenging ability were direct correlations to ascorbic acid and total flavonoid. Similar correlations were also reported in other studies about drying cranberries [27] and bitter melon [14].

3.2. Effect of microwave gap ratio on the hioactive compounds and antioxidant capacity of beetroots. The effect of microwave gap ratio on the intermittent microwave drying of the beetroot was carried at the power density of $2.0 \mathrm{~W} / \mathrm{g}$ and slice thickness of $4 \mathrm{~mm}$. Microwave gap ratio represents a ratio which is calculated by dividing the sum of the microwave on and off times by the microwave on times [12]. Microwave gap ratio value of 1 denotes the lack of off time and continuous microwave drying [20]. For example, if the total drying time is $3 \mathrm{~min}$ when the microwave gap ratio is 1 , then the microwave is on for $3 \mathrm{~min}$ (no off time). When the drying time is $6 \mathrm{~min}$ and the microwave gap ratio is 2, it means that the microwave on time is $3 \mathrm{~min}$ and the microwave off time is $3 \mathrm{~min}$. In a word, as microwave gap ratio increases, the off time of the microwave is gradually elongated. In this study, the drying time include off time and on time of microwave. A comparison of microwave gap ratio 1 with 2 to 4 , showed that the drying time of intermittent microwave drying were longer than that for continuous drying (microwave gap ratio of 1 , without microwave off times). Drying time increased gradually with increasing microwave gap ratio (Fig. 2). The drying time of beetroots at microwave gap ratio of 1 was the shortest $(35.4 \pm 2.6 \mathrm{~min}$ ), while the longest drying time $(127.0 \pm 5.9 \mathrm{~min})$ of beetroots appeared at microwave gap ratio of 4 . 


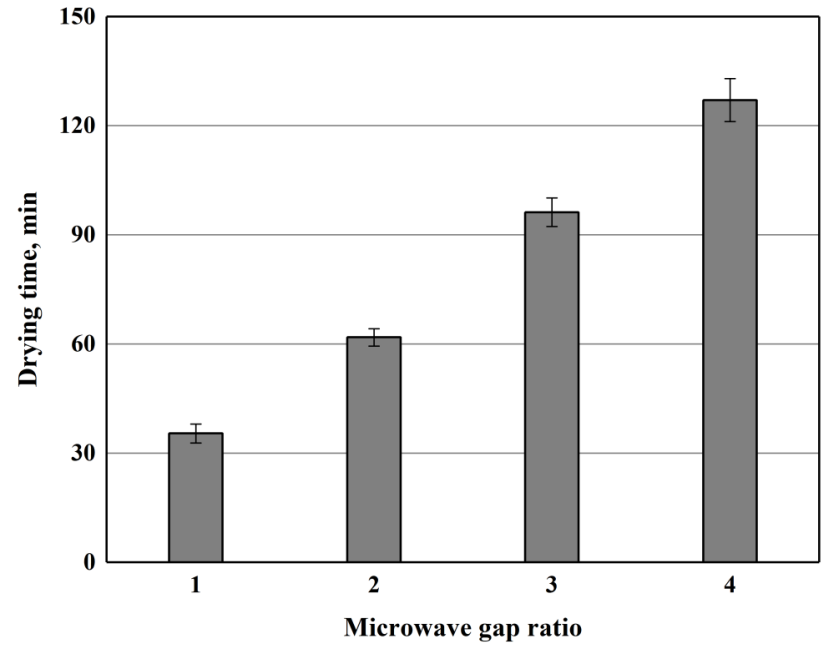

Fig. 2. Effect of different microwave gap ratios on the drying time of beetroots

Results for the change of betalains, ascorbic acid, total phenolic and total flavonoid in dried beetroots at different microwave gap ratios are exhibited in Table 3 .

The lowest contents of betacyanins $(1.09 \pm 0.03 \mathrm{mg} \mathrm{BE} / \mathrm{g})$ dried beetroots at microwave gap ratio of 4 , which required the longest drying time. The betacyanins content of beetroots reduced gradually with increasing microwave gap ratio from 1 to 4 . The results showed that the beetroots dried at microwave gap ratio of 1 had the highest betacyanins content $(1.65 \pm 0.03 \mathrm{mg} \mathrm{BE} / \mathrm{g})$, while the betaxanthins content of dried beetroots decreased with the increasing of microwave gap ratio from 2 to 4 . The highest content $(1.32 \pm 0.01 \mathrm{mg} \mathrm{IE} / \mathrm{g})$ of betaxanthin was observed at microwave gap ratio of 2 . For ascorbic acid content, the maximum content of $240.00 \pm 2.32 \mathrm{mg} / 100 \mathrm{~g}$ was occurred in dried beetroot at microwave gap ratio of 2 , but no significant difference was observed at microwave gap ratio of 1 and 2. Different microwave gap ratios provided a variety of TPC. The highest TPC $(9.99 \pm 0.06 \mathrm{mg} \mathrm{GAE} / \mathrm{g})$ of beetroots was obtained at microwave gap ratio of 2 . The TPC of beetroots significantly decreased with a decrease in microwave gap ratio from 2 to $4(p<0.05)$. As it can be seen from Table 3 , microwave gap ratio significantly affected TFC of dried beetroots $(p<0.05)$, and the highest TFC of $14.52 \pm 0.06 \mathrm{mg} \mathrm{RE} / \mathrm{g}$ was found in beetroots dried at microwave gap ratio of 2 . and betaxanthins $(0.86 \pm 0.01 \mathrm{mg} \mathrm{IE} / \mathrm{g})$ were found in the

Results showed that the changes in the contents of betacyanins, ascorbic acid and total phenolic in the beetroots dried at microwave gap ratio of 1 and 2 were insignificant $(p>0.05)$. Furthermore, the highest contents of betacyanins, ascorbic acid, total phenolic and total flavonoid appeared at microwave gap ratio of 2. The results indicated that bioactive compounds of dried beetroots maintained better as the microwave gap ratio of 2 in comparison with other microwave gap ratios.

Table 4 displays the antioxidant capacity of dried beetroots at different microwave gap ratios.

Table 4

Antioxidant capacity of dried beetroots at different microwave gap ratios

\begin{tabular}{|c|c|c|c|}
\hline Microwave gap ratio & DPPH, mg TE/g & FBAP, mg TE/g & ABTS, mg TE/g \\
\hline 1 & $5.26 \pm 0.04^{\mathrm{d}}$ & $14.12 \pm 0.05^{\mathrm{b}}$ & $21.22 \pm 0.31^{\mathrm{b}}$ \\
\hline 2 & $5.68 \pm 0.02^{\mathrm{a}}$ & $15.47 \pm 0.10^{\mathrm{a}}$ & $25.31 \pm 0.30^{\mathrm{a}}$ \\
\hline 3 & $5.57 \pm 0.02^{\mathrm{b}}$ & $12.25 \pm 0.17^{\mathrm{c}}$ & $20.82 \pm 0.12^{\mathrm{bc}}$ \\
\hline 4 & $5.43 \pm 0.06^{\mathrm{c}}$ & $11.85 \pm 0.15^{\mathrm{d}}$ & $20.57 \pm 0.19^{\mathrm{c}}$ \\
\hline
\end{tabular}

Note: values in the same column with different letters are significantly different $(p<0.05)$, according to the Duncan's test

Results showed that the antioxidant activity of dried beetroots was significantly affected by microwave gap ratios $(p<0.05)$. The lowest DPPH radical scavenging activity $(5.26 \pm 0.04 \mathrm{mg} \mathrm{TE} / \mathrm{g})$ was determined in dried beetroots at microwave gap ratio of 1 , whereas the DPPH radical scavenging activity decreased substantially as the microwave gap ratio increased from 2 to $4(p<0.05)$. The ferric-reducing ability of dried beetroots significantly decreased when the microwave gap ratio increased from 2 to $4(p<0.05)$. The lowest value of FRAP and ABTS assays were found in beetroots dried at microwave gap ratio of 4 . It can be observed that the $\mathrm{DPPH}$ radical scavenging activity, FRAP value and ABTS radical scavenging ability significantly decreased with the increase of microwave gap ratio from 2 to $4(p<0.05)$.

As shown in Tables 3, 4, the DPPH, FRAP, and ABTS values, which are highly associated with betaxanthins, ascorbic acid, TPC, and TFC of dried beetroots. The results were in agreement with the result in [28], which reported that the increase in antioxidant activities of samples depends not only on the presence of betalains, but also other polyphenols that may have been increased during the treatments.

Table 3

Contents of betalains, ascorbic acid, total phenolic and total flavonoid in dried beetroots as affected by different microwave gap ratios

\begin{tabular}{|c|c|c|c|c|}
\hline \multirow{2}{*}{ Bioactive compound } & \multicolumn{4}{|c|}{ Microwave gap ratio } \\
\cline { 2 - 5 } & 1 & 2 & 3 & 4 \\
\hline Betacyanins, mg BE/g & $1.65 \pm 0.03^{\mathrm{a}}$ & $1.60 \pm 0.01^{\mathrm{a}}$ & $1.45 \pm 0.01^{\mathrm{b}}$ & $1.09 \pm 0.03^{\mathrm{c}}$ \\
\hline Betaxanthins, mg IE/g & $1.11 \pm 0.01^{\mathrm{b}}$ & $1.32 \pm 0.01^{\mathrm{a}}$ & $1.10 \pm 0.01^{\mathrm{b}}$ & $0.86 \pm 0.01^{\mathrm{c}}$ \\
\hline Ascorbic acid, mg/100 g & $238.13 \pm 3.53^{\mathrm{a}}$ & $240.00 \pm 2.32^{\mathrm{a}}$ & $221.02 \pm 2.64^{\mathrm{c}}$ & $231.66 \pm 1.89^{\mathrm{b}}$ \\
\hline TPC, mg GAE/g & $9.94 \pm 0.11^{\mathrm{a}}$ & $9.99 \pm 0.06^{\mathrm{a}}$ & $9.71 \pm 0.06^{\mathrm{b}}$ & $9.20 \pm 0.04^{\mathrm{c}}$ \\
\hline TFC, mg RE/g & $12.92 \pm 0.24^{\mathrm{b}}$ & $14.52 \pm 0.06^{\mathrm{a}}$ & $10.97 \pm 0.12^{\mathrm{c}}$ & $10.56 \pm 0.23^{\mathrm{d}}$ \\
\hline
\end{tabular}

Note: different letters in the same row indicate that values аге significantly different $(p<0.05)$ according to the Duncan's test
3.3. Effect of slice thickness on the bioactive compounds and antioxidant capacity of beetroots. To explore the impact of slice thickness on the bioactive compounds and antioxidant capacity of the beetroots were dried at power density of $2.0 \mathrm{~W} / \mathrm{g}$, microwave gap ratio of 2 , and the thickness of slices ranged 2, 4, 6 , and $8 \mathrm{~mm}$. The effect of slice thickness on the drying time of beetroots is shown in Fig. 3.

It can be seen from Fig. 3, the drying time of beetroots increased with increasing thickness of beetroot slices. As the slice thickness increases, the distance of internal moisture migration to the surface 
increases, and the drying time increases accordingly. The shortest drying time was $54.6 \pm 2.9 \mathrm{~min}$ when the slice thickness was $2 \mathrm{~mm}$. The drying time of beetroots with slice thickness of $2 \mathrm{~mm}$ was only $52.6 \%$ of that of beetroots with thickness of $8 \mathrm{~mm}$. In other words, as the slice thickness of beetroots was increased from 2 to $8 \mathrm{~mm}$, the drying time increased by $90 \%$.

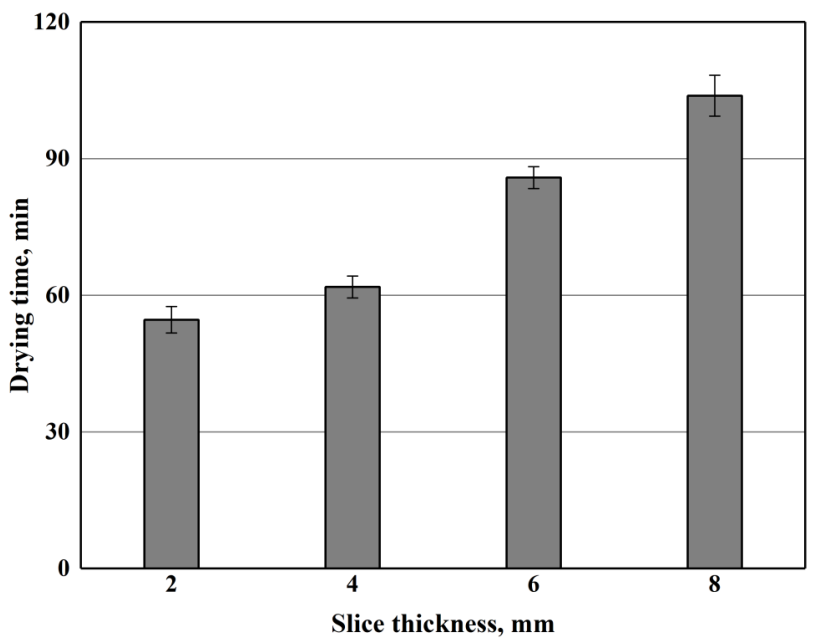

Fig. 3. Effect of different slice thickness on the drying time of beetrouts

Contents of betalains, ascorbic acid, total phenolic and total flavonoid of dried beetroots at different power densities are displayed in Table 5.

Impact of slice thickness on betalains, ascorbic acid, total phenolic and total flavonoid contents of dried beetroots

\begin{tabular}{|c|c|c|c|c|}
\hline \multirow{2}{*}{ Bioactive compounds } & \multicolumn{4}{|c|}{ Slice thickness, mm } \\
\cline { 2 - 5 } & 2 & 4 & 6 & 8 \\
\hline Betacyanins, mg BE/g & $1.73 \pm 0.01^{\mathrm{a}}$ & $1.60 \pm 0.01^{\mathrm{b}}$ & $0.93 \pm 0.01^{\mathrm{c}}$ & $0.89 \pm 0.01^{\mathrm{d}}$ \\
\hline Betaxanthins, mg IE/g & $1.32 \pm 0.01^{\mathrm{a}}$ & $1.32 \pm 0.01^{\mathrm{a}}$ & $0.89 \pm 0.01^{\mathrm{b}}$ & $0.83 \pm 0.01^{\mathrm{c}}$ \\
\hline Ascorbic acid, mg/100 g & $225.79 \pm 4.46^{\mathrm{b}}$ & $240.00 \pm 2.32^{\mathrm{a}}$ & $219.15 \pm 3.87^{\mathrm{b}}$ & $202.64 \pm 3.39^{\mathrm{c}}$ \\
\hline TPC, mg GAE/g & $9.47 \pm 0.02^{\mathrm{d}}$ & $9.99 \pm 0.06^{\mathrm{c}}$ & $12.54 \pm 0.13^{\mathrm{a}}$ & $10.48 \pm 0.14^{\mathrm{b}}$ \\
\hline TFC, mg RE/g & $11.84 \pm 0.18^{\mathrm{b}}$ & $14.52 \pm 0.06^{\mathrm{a}}$ & $11.64 \pm 0.08^{\mathrm{b}}$ & $10.52 \pm 0.33^{\mathrm{c}}$ \\
\hline
\end{tabular}

Note: different letters in the same row indicate that values аге significantly different $(p<0.05)$ according to the Duncan's test

The results showed that the content of betacyanins was found to be the highest $(1.73 \pm 0.01 \mathrm{mg} \mathrm{BE} / \mathrm{g})$ in the dried beetroots with thickness of $2 \mathrm{~mm}$. Meanwhile, contents of betacyanins and betaxanthins were found to be lowest in beetroots with slice thickness of $8 \mathrm{~mm}$. Interestingly, contents of betaxanthins were the same at slice thickness of $2 \mathrm{~mm}$ and $4 \mathrm{~mm}$. The ascorbic acid content in the dried beetroots was found in a range from $202.64 \pm 3.39$ to $240.00 \pm 2.32 \mathrm{mg} / 100 \mathrm{~g}$, being the highest value $(240.00 \pm 2.32 \mathrm{mg} / 100 \mathrm{~g})$ at slice thickness of $4 \mathrm{~mm}$. Betaxanthins contents of dried beetroots decreased significantly as the slice thickness increased from 4 to $8 \mathrm{~mm}(p<0.05)$. Regarding total phenolic, as the slice thickness increased from 2 to $6 \mathrm{~mm}$, TPC increased significantly $(p<0.05)$. The TPC reached to the lowest value of $9.47 \pm 0.02 \mathrm{mg} \mathrm{GAE} / \mathrm{g}$ at slice thickness of $2 \mathrm{~mm}$.
As shown in Table 5, the TFC of dried beetroots significantly decreased $(p<0.05)$ with increasing slice thickness from 4 to $8 \mathrm{~mm}$, and there was an insignificant difference in TFC at slice thickness of $2 \mathrm{~mm}$ and $6 \mathrm{~mm}$.

The antioxidant capacity of dried beetroots produced at different slice thicknesses is shown in Table 6 .

Antioxidant capacity of dried beetroots at different slice thicknesses

\begin{tabular}{|c|c|c|c|}
\hline Slice thickness, mm & DPPH, mg TE/g & FRAP, mg TE/g & ABTS, mg TE/g \\
\hline 2 & $3.75 \pm 0.05^{\mathrm{d}}$ & $12.28 \pm 0.04^{\mathrm{d}}$ & $18.20 \pm 0.39^{\mathrm{d}}$ \\
\hline 4 & $5.68 \pm 0.02^{\mathrm{a}}$ & $15.47 \pm 0.10^{\mathrm{a}}$ & $25.31 \pm 0.30^{\mathrm{a}}$ \\
\hline 6 & $5.34 \pm 0.05^{\mathrm{b}}$ & $14.76 \pm 0.10^{\mathrm{b}}$ & $22.79 \pm 0.19^{\mathrm{b}}$ \\
\hline 8 & $5.03 \pm 0.09^{\mathrm{c}}$ & $13.09 \pm 0.12^{\mathrm{c}}$ & $20.63 \pm 0.30^{\mathrm{c}}$ \\
\hline
\end{tabular}

Note: values in the same column with different letters are significantly different $(p<0.05)$, according to the Duncan's test

As shown in Table 6, slice thickness significantly affected $(p<0.05)$ the antioxidant capacity of dried beetroots. The DPPH radical scavenging activity and FRAP values decreased as the slice thickness increased from 4 to $8 \mathrm{~mm}$, and the lowest values were found at slice thickness of $2 \mathrm{~mm}$. Similarly to DPPH and FRAP values, Beetroots with slice thickness of $4 \mathrm{~mm}$ were found to show the highest ABTS radical scavenging activity $(25.31 \pm 0.30 \mathrm{mg} \mathrm{TE} / \mathrm{g})$. The lowest value of ABTS assay was $18.20 \pm 0.39 \mathrm{mg} \mathrm{TE} / \mathrm{g}$ at slice thickness of $2 \mathrm{~mm}$. It was found that the maximum antioxidant

Table 5 capacity of dried beetroot was at slice thickness of $4 \mathrm{~mm}$, which was highly associated with ascorbic acid content and TFC in dried beetroots. However, there are still some tasks that require further investigation in the future, such as which bioactive compounds are associated with the antioxidant activity of beetroots, and how these bioactive compounds affect the antioxidant activity of beetroots, etc.

In this research, the intermittent microwave drying conditions were designed based on the microwave drying system SAM-255. If the microwave drying equipment is different, the drying conditions may not be applicable.

The dehydrated beetroots obtained by intermittent microwave drying display strong antioxidant capacity, which can be used as an antioxidant in the food industry. In addition, the application of dried beetroots in food industry needs to be further studied. This study can provide a theoretical basis for beetroots processing, and can facilitate further development of dried beetroots.

\section{Conclusions}

The effect of intermittent microwave drying conditions, including power density, microwave gap ratio, and slice thickness on the bioactive compounds and antioxidant capacity of beetroots were investigated. All of the investigated factors significantly affected the drying time, bioactive compounds and antioxidant capacity of beetroots. 
The drying time decreased with the increase of power density, while increased significantly with the growth of slice thickness and microwave gap ratio.

Higher power density resulted in more loss in betacyanins, while higher radical scavenging ability of DPPH. The larger microwave gap ratio led to less contents of betalains, total phenolic and total flavonoid, and less values of FRAP and ABTS. Thicker of slice thickness caused more loss in betalains, ascorbic acid, total flavonoid, and lower antioxidant capacity.

In conclusion, appropriate power density, microwave gap ratio and slice thickness were conducive to maintaining higher bioactive compounds and antioxidant capacity of dried beetroots, and the effective intermittent microwave drying parameters were microwave gap ratio of 2 , power density of $2.0 \mathrm{~W} / \mathrm{g}$, and slice thickness of $4 \mathrm{~mm}$.

\section{Acknowledgements}

The authors would like to thank to Guangxi Key Laboratory of Health Care Food Science and Technology (Hezhou, China), and Hezhou Key Laboratory of Microwave Applications (Hezhou, China) for providing laboratory facilities and technical support. This work was funded by Guangxi First-class Discipline Food Science and Engineering Cultivation Project (GXYLXKP1816).

\section{References}

1. Chhikara, N., Kushwaha, K., Sharma, P., Gat, Y., Panghal, A. (2019). Bioactive compounds of beetroot and utilization in food processing industry: A critical review. Food Chemistry, 272, 192-200. doi: http://doi.org/10.1016/j.foodchem.2018.08.022

2. Clifford, T., Howatson, G., West, D., Stevenson, E. (2015). The Potential Benefits of Red Beetroot Supplementation in Health and Disease. Nutrients, 7 (4), 2801-2822. doi: http:// doi.org/10.3390/nu7042801

3. Fu, Y., Shi, J., Xie, S.-Y., Zhang, T.-Y., Soladoye, O. P., Aluko, R. E. (2020). Red Beetroot Betalains: Perspectives on Extraction, Processing, and Potential Health Benefits. Journal of Agricultural and Food Chemistry, 68 (42), 11595-11611. doi: http://doi.org/10.1021/acs.jafc.0c04241

4. Paciulli, M., Medina-Meza, I. G., Chiavaro, E., Barbosa-Cánovas, G. V. (2016). Impact of thermal and high pressure processing on quality parameters of beetroot (Beta vulgaris L.). LWT - Food Science and Technology, 68, 98-104. doi: http:// doi.org/10.1016/j.lwt.2015.12.029

5. Nistor, O.-V., Seremet (Ceclu), L., Andronoiu, D. G., Rudi, L., Botez, E. (2017). Influence of different drying methods on the physicochemical properties of red beetroot (Beta vulgaris L. var. Cylindra). Food Chemistry, 236, 59-67. doi: http://doi.org/ 10.1016/j.foodchem.2017.04.129

6. Jin, W., Zhang, M., Shi, W. (2018). Evaluation of ultrasound pretreatment and drying methods on selected quality attributes of bitter melon (Momordica charantia L.). Drying Technology, 37 (3), 387-396. doi: http://doi.org/10.1080/07373937.2018.1458735

7. Alibas, I. (2007). Microwave, air and combined microwave-airdrying parameters of pumpkin slices. LWT - Food Science and Technology, 40 (8), 1445-1451. doi: http://doi.org/10.1016/ j.lwt.2006.09.002

8. Arikan, M. F., Ayhan, Z., Soysal, Y., Esturk, O. (2011). Drying Characteristics and Quality Parameters of MicrowaveDried Grated Carrots. Food and Bioprocess Technology, 5 (8), 3217-3229. doi: http://doi.org/10.1007/s11947-011-0682-8

9. Junqueira, J. R. de J., Corrêa, J. L. G., Ernesto, D. B. (2017). Microwave, convective, and intermittent microwave-convective drying of pulsed vacuum osmodehydrated pumpkin slices. Journal of Food Processing and Preservation, 41 (6), e13250. doi: http:// doi.org/10.1111/jfpp.13250
10. Vadivambal, R., Jayas, D. S. (2008). Non-uniform Temperature Distribution During Microwave Heating of Food Materials A Review. Food and Bioprocess Technology, 3 (2), 161-171. doi: http://doi.org/10.1007/s11947-008-0136-0

11. Wei, Q., Huang, J., Zhang, Z., Lia, D., Liu, C., Xiao, Y. et. al. (2018). Effects of different combined drying methods on drying uniformity and quality of dried taro slices. Drying Technology, 37 (3), 322-330. doi: http://doi.org/10.1080/07373937.2018.1445639

12. Gunasekaran, S. (1999). Pulsed microwave-vacuum drying of food materials. Drying Technology, 17 (3), 395-412. doi: http:// doi.org/10.1080/07373939908917542

13. Stintzing, F. C., Herbach, K. M., Mosshammer, M. R., Carle, R., Yi, W., Sellappan, S. et. al. (2005). Color, betalain pattern, and antioxidant properties of cactus pear (Opuntia spp.) clones. Journal of Agricultural and Food Chemistry, 53 (2), 442-451. doi: http://doi.org/10.1021/jf048751y

14. Nguyen, T.-V.-L., Nguyen, Q.-N., Nguyen, P.-B.-D., Tran, B.-L. Huynh, P.-T. (2020). Effects of drying conditions in low-temperature microwave-assisted drying on bioactive compounds and antioxidant activity of dehydrated bitter melon (Momordica charantia L.). Food Science and Nutrition, 8 (7), 3826-3834. doi: http://doi.org/10.1002/fsn3.1676

15. Emilio, A. P., Laura, A. de la R., Ryszard, A., Fereidoon, S. (2011). Antioxidant activity of fresh and processed Jalapeño and Serrano peppers. Journal of Agricultural and Food Chemistry, 59 (1), 163-173. doi: http://doi.org/10.1021/jf103434u

16. De Souza, V. R., Pereira, P. A. P., da Silva, T. L. T., de Oliveira Lima, L. C., Pio, R., Queiroz, F. (2014). Determination of the bioactive compounds, antioxidant activity and chemical composition of Brazilian blackberry, red raspberry, strawberry, blueberry and sweet cherry fruits. Food Chemistry, 156, 362-368. doi: http://doi.org/10.1016/j.foodchem.2014.01.125

17. Brand-Williams, W., Cuvelier, M. E., Berset, C. (1995). Use of a free radical method to evaluate antioxidant activity. $L W T-$ Food Science and Technology, 28 (1), 25-30. doi: http://doi.org/ 10.1016/s0023-6438(95)80008-5

18. Benzie, I. F. F., Strain, J. J. (1996). The Ferric Reducing Ability of Plasma (FRAP) as a Measure of «Antioxidant Power»: The FRAP Assay. Analytical Biochemistry, 239 (1), 70-76. doi: http://doi.org/10.1006/abio.1996.0292

19. Re, R., Pellegrini, N., Proteggente, A., Pannala, A., Yang, M., Rice-Evans, C. (1999). Antioxidant activity applying an improved ABTS radical cation decolorization assay. Free Radical Biology and Medicine, 26 (9-10), 1231-1237. doi: http://doi.org/ 10.1016/s0891-5849(98)00315-3

20. Bing, L., Jun, C., Ai-Guo, F., Yan, L., Qun, Y., Chuan, L., Zhen-Hua, D. (2018). Effects of osmotic dehydration vacuummicrowave drying on the properties of tilapia fillets. Czech Journal of Food Sciences, 36 (2), 169-174. doi: http://doi.org/ 10.17221/137/2017-cjfs

21. Horuz, E., Jaafar, H. J., Maskan, M. (2016). Ultrasonication as pretreatment for drying of tomato slices in a hot air-microwave hybrid oven. Drying Technology, 35 (7), 849-859. doi: http:// doi.org/10.1080/07373937.2016.1222538

22. Izli, N., Polat, A. (2019). Effect of convective and microwave methods on drying characteristics, color, rehydration and microstructure properties of ginger. Food Science and Technology (Campinas), 39 (10), 652-659. doi: http://doi.org/10.1590/fst.04518

23. Dudley, G. B., Richert, R., Stiegman, A. (2015). On the existence of and mechanism for microwave-specific reaction rate enhancement. Chemical Science, 6 (4), 2144-2152. doi: http:// doi.org/10.1002/chin.201521253

24. Mao, L.-C., Pan, X., Que, F., Fang, X.-H. (2005). Antioxidant properties of water and ethanol extracts from hot air-dried and freeze-dried daylily flowers. European Food Research and Technology, 222 (3-4), 236-241. doi: http://doi.org/10.1007/ s00217-005-0007-0

25. Inchuen, S., Narkrugsa, W., Pornchaloempong, P. (2010). Effect of drying methods on chemical composition, color and antioxidant properties of Thai red curry powder. Kasetsart Journal (Nature Science), 44 (1), 142-151. Available at: https:// www.researchgate.net/publication/266224049 
26. Figiel, A. (2010). Drying kinetics and quality of beetroots dehydrated by combination of convective and vacuum-microwave methods. Journal of Food Engineering, 98 (4), 461-470. doi: http://doi.org/10.1016/j.jfoodeng.2010.01.029

27. Zielinska, M., Zielinska, D. (2019). Effects of freezing, convective and microwave-vacuum drying on the content of bioactive compounds and color of cranberries. LWT, 104, 202-209. doi: http://doi.org/10.1016/j.lwt.2019.01.041

28. Ravichandran, K., Saw, N. M. M. T., Mohdaly, A. A. A. Gabr, A. M. M., Kastell, A., Riedel, H. et. al. (2013). Impact of processing of red beet on betalain content and antioxidant activity. Food Research International, 50 (2), 670-675. doi: http://doi.org/10.1016/j.foodres.2011.07.002

Yan Liu, Postgraduate Student, Department of Engineering Tech nologies for Food Production, Sumy National Agrarian University, Sumy, Ukraine; School of Food and Biological Engineering, Hezhou
University, Hezhou, China, ORCID: https://orcid.org/0000-0002$6322-7013$

$\triangle$ Zhenhua Duan, PhD, Professor, School of Food and Biological Engineering, Hezhou University, Hezhou, China, e-mail:dzh65@126.com, ORCID: https://orcid.org/0000-0002-9283-3629

Sergey Sabadash, PhD, Associate Professor, Department of Engineering Technologies for Food Production, Sumy National Agrarian University, Sumy, Ukraine, ORCID: https://orcid.org/0000-00020371-8208

Feifei Shang, Postgraduate Student, Department of Technology and Food Safety, Sumy National Agrarian University, Sumy, Ukraine; School of Food and Biological Engineering, Hezhou University, Hezhou, China, ORCID: https://orcid.org/0000-0001-7648-9568

$\triangle$ Corresponding author

UDC 634.614:631.361

DOI: $10.15587 / 2706-5448.2022 .253931$ Article type «Reports on Research Projects»

\section{Dare Ibiyeye, Oluwatoyin Olunloyo, Adeniyi Aderemi, Ileri-Oluwa Emmanuel, Abisayo Akala, Oluwaseun Dwolola}

\section{DESIGN AND DEVELOPMENT OF A PALM KERNEL NUT CRACKING UNIT}

The object of this research is the cracking of the nuts of oil palm (Elaesis guineensis). The oil palm tree is one of the greatest economic assets a nation can have, provided its importance is realized and fully harnessed. After the oil extraction of palm oil from the palm fruits, virtually all methods involved in palm kernel nut cracking both in traditional and small-scale exist in scattered or separate units of operations. Hence, this research focused on designing a palm nut kernel cracking unit incorporating a separator in form of a screen to separate cracked palm kernel nut shell from kernel. The result shows that there were significant difference $(p \leq 0.05)$ among the moisture content of the palm nuts, shaft speed of the machine and weight (feed rate), having a significant difference between:

- moisture content of the palm nut and the shaft speed of the cracker;

- moisture content and feed rate;

- shaft speed and feed rate.

There exist interaction between cracked, uncracked shell, damaged, undamaged kernel, and palm kernel nut breakage ratio. While, there was no significant difference among interaction between moisture content, shaft speed and feed weight. The result also indicated that for the highest speed of 1,800 rpm at a feed rate of $700 \mathrm{~kg} / \mathrm{h}$ for all moisture contents, the cracking efficiency was between 10 to $90 \%$, which implies that the kernel cracking efficiency increases with an increase in machine speed. However, it was observed that higher cracking efficiency was at the cost of higher kernel damage for all cracking speeds and feed rates, which is a problem. The kernel breakage ratio ranged from 1.040-7.85 for all feed rates and moisture contents. The kernel breakage ratio increased with moisture content and cracking speed but decreases with feed rate weight.

Keywords: Elaeis guineensis, nut cracking unit, cracking speed, kernel breakage ratio, moisture content.

\section{How to cite}

Ibiyeye, D., Olunloyo, O., Aderemi, A., Emmanuel, I.-O., Akala, A., Owolola, O. (2022). Design and development of a palm kernel nut cracking unit Technology Audit and Production Reserves, 1 (3 (63)), 30-44. doi: http://doi.org/10.15587/2706-5448.2022.253931

\section{Introduction}

The oil palm (Elaeis guineensis) originated from the tropical rain forest region of Africa. But due to its economic important as the world highest yielding source of edible and technical oils, it is now grown as a plantation crop in most countries with high rainfall in tropical climates within $23^{\circ} \mathrm{N}$ to $23^{\circ} \mathrm{S}$ of the equator and longitude $17^{\circ} \mathrm{W}$ 